\title{
Fabrication of Surface Layer Enriched with Zinc on AlSi17 Aluminium Cast Alloy by Hot-Dip Galvanizing
}

\author{
Tomasz Bucki $^{\mathbf{*} *}$, Dana Bolibruchová ${ }^{b}$ \\ ${ }^{a}$ Kielce University of Technology, Faculty of Mechatronics and Mechanical Engineering, Tysiąclecia Państwa Polskiego 7 Ave., \\ 25314 Kielce, Poland \\ bUniversity of Zilina, Department of Technological Engineering, Univerzitna 8215/1 St., 01026 Zilina, Slovakia \\ *e-mail: tbucki@tu.kielce.pl
}

(c) 2019 Authors. This is an open access publication which can be used, distributed and reproduced in any medium according to the Creative Commons CC-BY 4.0 License requiring that the original work has been properly cited.

Received: 5 September 2019/Accepted: 21 January 2020/ Published online: 31 January 2020

This article is published with open access at AGH University of Science and Technology Press

\begin{abstract}
The paper deals with the fabrication of the surface layer enriched with Zn on AlSi17 aluminium alloy to modify the microstructure and surface properties of the alloy. The continuous surface layer was fabricated on the AlSi17 substrate by the hot-dip galvanizing of AlSi17 for $15 \mathrm{~min}$ in a $\mathrm{Zn}$ bath heated to $450^{\circ} \mathrm{C}$. The thickness of the layer was about $100 \mu \mathrm{m}$. The layer was characterised by a multi-component microstructure containing the regions of a solid solution of $\mathrm{Al}$ in $\mathrm{Zn}$ and dendrites of a eutectoid composed of a solid solution of $\mathrm{Al}$ in $\mathrm{Zn}$ and a solid solution of $\mathrm{Zn}$ in $\mathrm{Al}$. In the layer, fine particles of Si with a regular shape were distributed. The results indicated that these Si particles formed by the action of $\mathrm{Zn}$ on the eutectic Si precipitations in the AlSi17 substrate. In the microstructure, large primary Si crystals and multi-phase precipitations, originating from the substrate, were also observed. The surface layer had much higher microhardness than the AlSi17 substrate. The results showed that hot-dip galvanizing can be used to modify the microstructure and properties of the surface layer of AlSi17. The study indicates the possibility of conducting further research on the fabrication of joints between AlSi17 and other metallic materials using a Zn interlayer fabricated by hot-dip galvanizing.
\end{abstract}

\section{Keywords:}

aluminium alloy, zinc, surface layer, hot-dip galvanizing, microstructure, microhardness

\section{INTRODUCTION}

Aluminium cast alloys are used in many fields of the industry due to their low density, combined with favourable casting and mechanical properties. The vast majority of aluminium alloys are characterised by good corrosion resistance in the natural atmosphere, sea water and many other chemical compounds $[1,2]$. The good corrosion resistance is a result of the presence of a thin layer of aluminium oxide on the surface. This layer is a tight barrier preventing the aggressive action of the atmosphere on the metal. However, joining the aluminium alloys with other metals is difficult because of the occurrence of a passive layer on the surface. The layers enriched with zinc on the surface of the aluminium alloys are fabricated to improve the properties of the joints between them and other metallic materials. The literature data include the studies on the effect of a $\mathrm{Zn}$ interlayer on the microstructure and properties of pure $\mathrm{Al}$ or $\mathrm{Al}$ alloy combined with other metals such as $\mathrm{Mg}$ [3-8] or $\mathrm{Cu}$ [9], fabricated by brazing [3], friction stir welding [4], diffusion bonding [5], welding [6, 7], compound casting [8] or ultrasonic welding [9]. The combination of an $\mathrm{Al}$ alloy with other metals with the use of a $\mathrm{Zn}$ interlayer requires the enrichment of the $\mathrm{Al}$ surface with $\mathrm{Zn}$ prior to the joining process. The layers enriched with $\mathrm{Zn}$ on Al alloys can be produced by hot-dipping [3-5], diffusion bonding [8] electrolysis [10-12], or electroless deposition $[10,13]$. Some methods allow the application of $\mathrm{Zn}$ between $\mathrm{Al}$ alloy and other metal during joining process $[6,7,9]$.

According to Al-Si phase diagram [14], the AlSi17 alloy is a hyper-eutectic alloy. The microstructure of such an alloy contains the eutectic composed of $\mathrm{Si}$ (the solubility of $\mathrm{Al}$ in $\mathrm{Si}$ is negligibly low) and a solid solution of $\mathrm{Si}$ in $\mathrm{Al}$. In the eutectic, primary Si crystals are distributed. The content of impurities, alloying elements and solidification conditions may cause the occurrence of additional structural components. Analysis of Al-Si [14], Al-Zn [15], Si-Zn [16] and $\mathrm{Al}-\mathrm{Si}-\mathrm{Zn}$ [17] phase diagrams shows that the addition of $\mathrm{Zn}$ to 
theAlSi17 alloy canlead to significantchangesinthestructure. In the $\mathrm{Al}-\mathrm{Zn}$ system at $381^{\circ} \mathrm{C}$ the eutectic transformation occurs. The product of this transformation is a eutectic composed of a solid solution of $\mathrm{Al}$ in $\mathrm{Zn}$ and a $\beta^{\prime}$ phase, which is stable at high temperatures. Further cooling leads to the eutectoid transformation at $277^{\circ} \mathrm{C}$, where $\beta^{\prime}$ phase transforms to a eutectoid mixture composed of a solid solution of $\mathrm{Al}$ in $\mathrm{Zn}$ and a solid solution of $\mathrm{Zn}$ in $\mathrm{Al}[15,17]$. The authors of Si-Zn [16] and Al-Si-Zn [17] diagrams identified that the solubility of $\mathrm{Zn}$ in $\mathrm{Si}$ and $\mathrm{Si}$ in $\mathrm{Zn}$ is negligibly low.

The presented work includes the analysis of the microstructure and phase composition of the surface layer enriched with zinc on an AlSi17 aluminium cast alloy by hot-dip galvanizing and the determination of the effect of $\mathrm{Zn}$ on the microhardness of the layer.

\section{EXPERIMENTAL PROCEDURE}

AlSi17 aluminium cast alloy $(17.18 \% \mathrm{Si}, 1.22 \% \mathrm{Mg}, 0.82 \% \mathrm{Ni}$, $0.72 \% \mathrm{Cu}, 0.25 \% \mathrm{Fe}, 0.02 \% \mathrm{Zn}$, balance of $\mathrm{Al}$ ) was selected as the substrate material. Specimens with dimensions of $20 \times 10 \times 10 \mathrm{~mm}$ were cut out from the ingot. The surfaces of the specimens were prepared by means of grinding with abrasive papers up to 800 grit and cleaning in ethanol. The bath for hot-dipping was prepared by melting $\mathrm{Zn}$ $(99.995 \% \mathrm{Zn})$ in a graphite crucible. The process parameters were selected on the basis of the tests and literature data. The surface layer enriched with zinc on AlSi17 was fabricated by dipping of the specimens for $15 \mathrm{~min}$ in a $\mathrm{Zn}$ bath heated to $450^{\circ} \mathrm{C}$. After taking them out of the bath, the specimens were cooled in the air.

The cross-sections for microscopic observations were prepared by cutting the specimens using a low speed precision cutting machine and grinding them with an automatic grinding and polishing machine. Final polishing was performed using $0.3 \mu \mathrm{m}$ polycrystalline alumina polishing suspension. Microscopic observations were conducted for non-etched specimens and after etching in 5\% solution of sulfuric acid in a Nikon ECLIPSE MA 200 Optical Microscope (OM). The chemical composition was analysed in a JEOL JSM-7100F Scanning Electron Microscope connected with an energy dispersive X-ray spectroscopy (SEM/EDS). The phase composition of the surface layer enriched with $\mathrm{Zn}$ on AlSi17 was analysed by EDS analysis on the basis of $\mathrm{Al}-\mathrm{Si}, \mathrm{Al}-\mathrm{Zn}, \mathrm{Si}-\mathrm{Zn}$ and $\mathrm{Al}-\mathrm{Si}-\mathrm{Zn}$ phase equilibrium diagrams [14-17]. The microhardness was measured by means of the Vickers method at a load of $50 \mathrm{~g}$, using an Innovatest Nexus 4000 microhardness tester.

\section{RESULTS AND DISCUSSION}

Figure 1a shows the microstructure of the surface layer enriched with zinc on AlSi17 fabricated by hot-dip galvanizing at $450^{\circ} \mathrm{C}$ for $15 \mathrm{~min}$, observed in $\mathrm{OM}$ without etching. The microstructure indicates that as a result of the contact of AlSi17 with molten $\mathrm{Zn}$, the continuous surface layer with a thickness of about $100 \mu \mathrm{m}$ was formed on the AlSi17 substrate. The etching of the specimen revealed the complex structure of the layer (Fig. 1b).
Figure 2 presents the results of EDS linear analysis executed throughout the surface layer and the distribution of Al, Si and Zn. From the results, it is clear that as it moves from the AlSi17 substrate to the outer part of the layer, the Zn content increases, while the amount of Al decreases. In the produced layer, the content of $\mathrm{Si}$ is observed around the dark areas.

a)

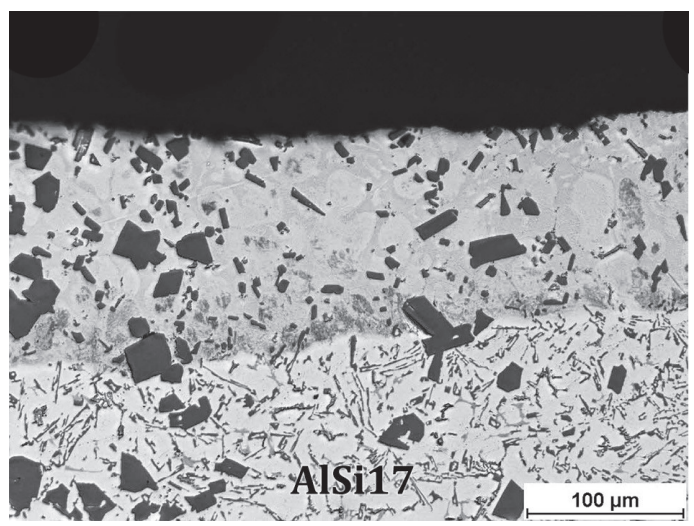

b)

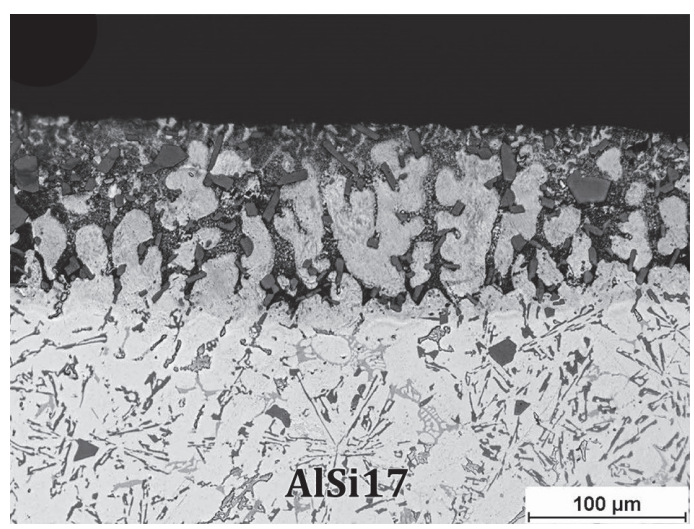

Fig. 1. OM images of the surface layer enriched with zinc on AlSi17 fabricated by hot-dip galvanizing: a) non-etched specimen; b) specimen after etching

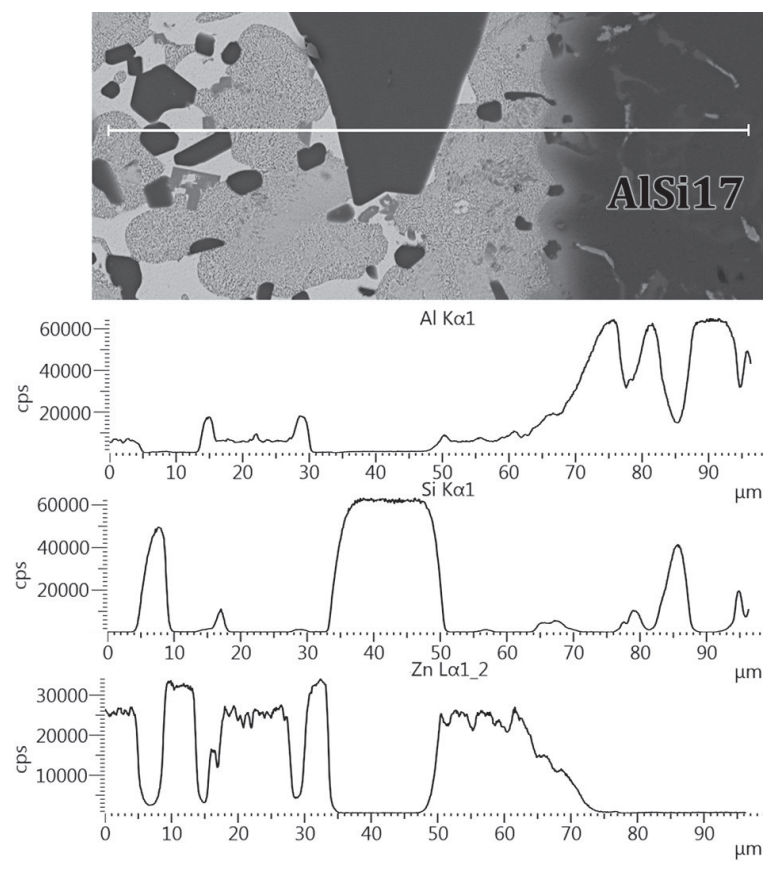

Fig. 2. Results of EDS linear analysis throughout the surface layer presenting the distribution of $\mathrm{Al}, \mathrm{Si}$ and $\mathrm{Zn}$ 
Figure 3 shows the SEM image of the inner part of surface layer with marked points where the chemical composition was examined by means of EDS analysis. The results of the analysis are summarised in Table 1.

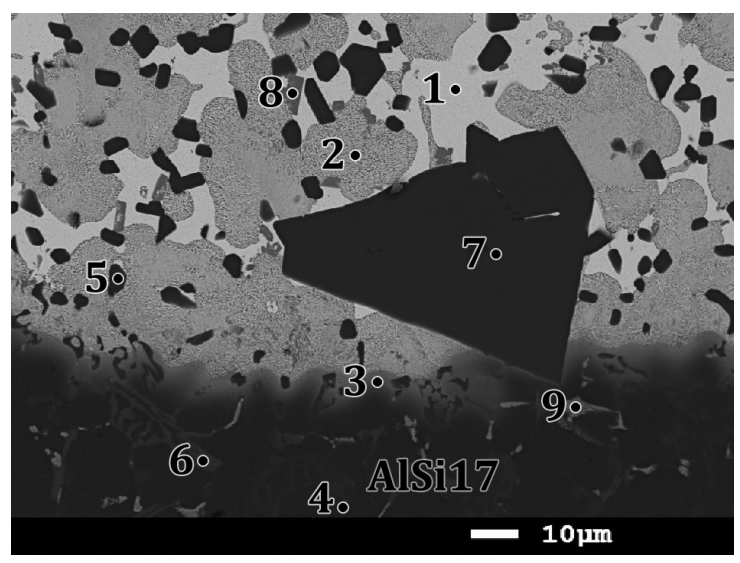

Fig. 3. SEM image of the inner part of the surface layer with the points where the chemical composition was analysed (explanation $1-9$ in text)

The microstructure of the analysed part of the layer consisted mainly of the white areas with two-phase dendrites and dark particles. The composition in point 1 indicated that the white areas are composed of a solid solution of $\mathrm{Al}$ in $\mathrm{Zn}$. The results for the dendrite marked as 2 corresponded to the composition of a eutectoid composed of a solid solution of $\mathrm{Al}$ in $\mathrm{Zn}$ and a solid solution of $\mathrm{Zn}$ and probably $\mathrm{Si}$ in Al. The analysis of the chemical composition of the substrate in the immediate vicinity of the layer (point 3) and at the depth of about $30 \mu \mathrm{m}$ from the layer (point 4) showed that the AlSi17 substrate contained a solid solution of $\mathrm{Si}$ in $\mathrm{Al}$ and it was enriched with $\mathrm{Zn}$ in the region immediately adjacent to the layer. Subsequent results suggested that dark particles marked as 5 are Si precipitations. The comparison of the shape of these particles with the form of precipitations of eutectic Si in the AlSi17 substrate (marked as 6) indicated that during the fabrication of the layer, the $\mathrm{Zn}$ affects the precipitations of eutectic $\mathrm{Si}$ and, consequently, leads to their shape changing to a more regular one.
The composition of the large, dark particle marked as 7 shows that it is composed of Si. The observation in SEM revealed that this Si particle is a primary Si crystal from the substrate, and the Zn during fabrication of the layer did not affect it visibly. The layer also contained fine, grey particles, marked as 8. The results of the analysis showed that their composition is similar to the composition of the multi-component phase containing $\mathrm{Mn}$ and Fe located in the substrate, marked as point 9 .

In the outer part of the layer, shown in Figure 4, a slightly different microstructure was observed. The results of the EDS analysis from the regions marked in the figure are listed in Table 1. Close to the surface, the two-phase grey precipitations with an elongated shape (point 10) coexisted with the white areas, marked with the number 11 . The results for the grey areas indicated a eutectoid (a solid solution of $\mathrm{Al}$ in $\mathrm{Zn}$ and a solid solution of $\mathrm{Zn}$ and probably $\mathrm{Si}$ in $\mathrm{Al}$, while the chemical composition of the white areas corresponded to a solid solution of $\mathrm{Al}$ in $\mathrm{Zn}$. The results of the analysis of the microstructure and phase diagrams $[15,17]$ suggest that the elongated shape of the eutectoid precipitations on the background of a solid solution of $\mathrm{Al}$ in $\mathrm{Zn}$ may be a result of the eutectic transformation that occurs during solidification.

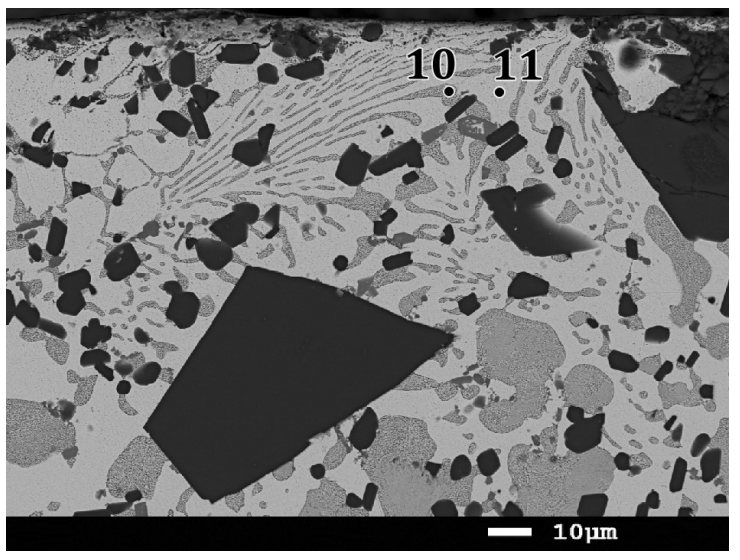

Fig. 4. SEM image of the outer part of the surface layer with the points where the chemical composition was analysed (explanation 10 and 11 in text)

Table 1

Results of EDS quantitative point analysis [at.\%]

\begin{tabular}{ccccc}
\hline Point & Al & Si & Zn & Other \\
\hline 1 & 3.03 & - & 96.97 & - \\
\hline 2 & 39.04 & 0.34 & 60.62 & - \\
\hline 3 & 87.63 & 1.10 & 11.27 & - \\
\hline 4 & 98.37 & 1.63 & - & - \\
\hline 5 & 0.51 & 99.49 & - & - \\
\hline 6 & 0.37 & 99.61 & -0.02 & - \\
\hline 7 & 0.17 & 99.83 & 3.14 & Mn: 5.48, Fe: 9.74 \\
\hline 8 & 67.71 & 13.93 & - & Mn: 6.11, Fe: 9.96 \\
\hline 9 & 70.64 & 13.29 & 54.90 & - \\
\hline 10 & 44.87 & 0.23 & 96.44 & - \\
\hline 11 & 3.56 & - & &
\end{tabular}


Figure 5 shows the traces of the Vickers microhardness measurements in representative regions of the produced layer and the AlSi17 substrate. The result obtained for the substrate was 65.3HV0.05, while in the surface layer enriched with $\mathrm{Zn}$, the microhardness was much higher and rose to 96.1-104.4 HV0.05.

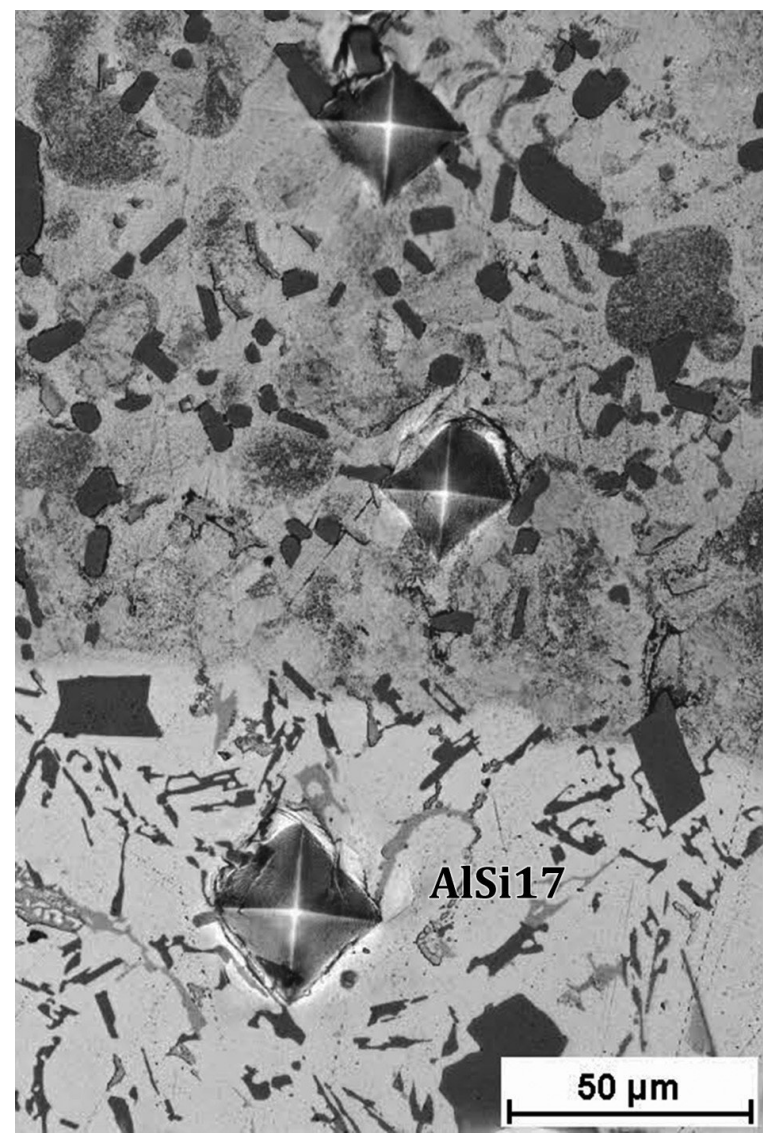

Fig. 5. Surface layer enriched with Zn on AlSi17 with traces of the Vickers microhardness measurements

The results of the study showed that continuous surface layer enriched with $\mathrm{Zn}$ was fabricated on the AlSi17 substrate by the hot-dip galvanizing process. The layer was characterised by a uniform thickness and higher microhardness than the AlSi17 substrate. The properties of the surface layer indicate its potential for further research focused on the fabrication of joints between AlSi17 and other metallic materials using an $\mathrm{Zn}$ interlayer fabricated by hot-dip galvanizing.

\section{CONCLUSIONS}

The surface layer enriched with Zn, characterised by a uniform thickness of about $100 \mu \mathrm{m}$, was formed on the AlSi17 substrate as a result of the specimens being dipped for $15 \mathrm{~min}$ in a $\mathrm{Zn}$ bath heated to $450^{\circ} \mathrm{C}$. The analysis of the microstructure indicated that the layer had a multi-component microstructure containing the regions of a solid solution of $\mathrm{Al}$ in $\mathrm{Zn}$ and dendrites composed of a eutectoid (a solid solution of $\mathrm{Al}$ in $\mathrm{Zn}$ and a solid solution of $\mathrm{Zn}$ in $\mathrm{Al}$ ). The layer contained fine particles of an $\mathrm{Si}$, regular in shape, formed, according to the results, by the action of $\mathrm{Zn}$ on the precipitations of eutectic $\mathrm{Si}$ in the AlSi17 substrate. In the layer, large primary Si crystals and multi-phase precipitations originating from the substrate were also observed. In the microstructure, a thin region of the substrate immediately adjacent to the layer where the solid solution of Si in $\mathrm{Al}$ was enriched with $\mathrm{Zn}$ was observed. The surface layer was characterised by much higher microhardness in comparison with the AlSi17 substrate.

\section{REFERENCES}

[1] Hatch J.E. (1984). ALUMINUM. Properties and Physical Metallurgy. Ohio: American Society for Metals.

[2] Pastircak R., Scury J., Bruna M. \& Bolibruchová D. (2017). Effect of Technological Parameters on the AlSi12 Alloy Microstructure during Crystallization under Pressure. Archives of Foundry Engineering, 17(2), 75-78. Doi: 10.1515/afe-2017-0054

[3] Liu L., Tan J. \& Liu X. (2007). Reactive brazing of Al alloy to Mg alloy using zinc-based brazing alloy. Materials Letters, 61, 2373-2377. Doi:10.1016/j.matlet.2006.09.016

[4] Xu R.Z., Ni D.R., Yang Q., Liu C.Z. \& Ma Z.Y. (2016). Influence of Zn coating on friction stir spot welded magnesium-aluminium joint. Science and Technology of Welding and Joining, 22(6), 512-519. Doi: 10.1080/13621718.2016.1266735

[5] Zhao L.M. \& Zhang Z.D. (2008). Effect of Zn alloy interlayer on interface microstructure and strength of diffusion-bonded Mg-Al joints. Scripta Materialia, 58(4), 283-286. Doi: 10.1016/j.scriptamat.2007.10.006

[6] Zhang H.T. \& Song J.Q. (2011). Microstructural evolution of aluminum/magnesium lap joints welded using MIG process with zinc foil as an interlayer. Materials Letters, 65, 3292-3294. Doi: 10.1016/j.matlet.2011.05.080

[7] Zhang H.T., Dai X.Y. \& Feng J.C. (2014). Joining of aluminum and magnesium via pre-roll-assisted A-TIG welding with Zn interlayer. Materials Letters, 122, 49-51. Doi: 10.1016/ j.matlet.2014.02.008

[8] Mola R., Bucki T. \& Gwozdzik M. (2018). The Effect of a Zinc Interlayer on the Microstructure and Mechanical Properties of a Magnesium Alloy (AZ31)-Aluminum Alloy (6060) Joint produced by Liquid-Solid Compound Casting. Journal of Minerals, Metals \& Materials Society, 71(6), 2078-2086. Doi: 10.1007/ s11837-019-03405-y

[9] Balasundaram R., Patel V.K., Bhole S.D. \& Chen D.L. (2014). Effect of zinc interlayer on ultrasonic spot welded aluminum-to-copper joints. Materials Science and Engineering: A, 607(3), 277-286. Doi: 10.1016/j.msea.2014.03.135

[10] Keller F. \& Zelley W.G. (1950). Conditioning Aluminum Alloys for Electroplating. Journal of the Electrochemical Society, 97(4), 143-151. Doi: 10.1149/1.2777981

[11] Zelley W.G. (1953). Formation of Immersion Zinc Coatings on Aluminum. Journal of the Electrochemical Society, 100(7), 328-333. Doi: 10.1149/1.2781127

[12] Saidman S.B., Munoz A.G. \& Bessone J.B. (1999). Electrodeposition of indium and zinc on aluminium. Journal of Applied Electrochemistry, 2, 245-251. Doi: 10.1039/c8gc03389g

[13] Wu J., Chen Z., Si Y.S., Guo Z.C. \& Sun X.I. (2011). Two-Step Electroless Zinc Plating Process of 1060 Aluminum. Materials Protection, 607(05), 37-39.

[14] Murray J.L. \& McAIister A.J. (1984). The AI-Si (Aluminum-Silicon) System. Bulletin of Alloy Phase Diagrams, 5, 74-84. Doi: $10.1007 /$ BF02868729

[15] Murray J.L. (1983). The Al-Zn (Aluminum-Zinc) System. Bulletin of Alloy Phase Diagrams, 4, 55-73. Doi: 10.1007/ BF02880321

[16] Olesinski R.W. \& Abbaschian G.J. (1985). The Si-Zn (Silicon-Zinc) system. Bulletin of Alloy Phase Diagrams, 6, 545-548. Doi: $10.1007 / \mathrm{BF} 02887156$

[17] Jacobs M.H.G. \& Spencer P.J. (1996). A critical thermodynamic evaluation of the systems Si-Zn and Al-Si-Zn. Calphad, 20(3), 307-320. Doi: 10.1016/S0364-5916(96)00033-8 